\title{
As ciências da história no século XIX
}

\author{
The sciences of history in the $19^{\text {th }}$ century
}

MALERBA, Jurandir (org.). Lições de história: o caminho da ciência no longo século XIX. Rio de Janeiro: Editora FGV; Porto Alegre: Edipucrs, 2010, 492 p.

\section{Eduardo Wright Cardoso}

edowc@yahoo.com.br

Doutorando - Bolsista CAPES

Pontifícia Universidade Católica do Rio de Janeiro

Rua das Laranjeiras, 336/901 - bloco A - Laranjeiras

22240-003 - Rio de Janeiro - RJ

Brasil

Palavras-chave

História da historiografia; História científica; Genealogia.

Keywords

History of historiography; Scientific history; Genealogy. 
Os estudos de história da historiografia têm recebido diferentes aportes e têm tido vários desdobramentos em anos recentes. Assim, foram criadas não apenas disciplinas específicas, mas igualmente se multiplicaram as linhas de pesquisa e os eventos relacionados à área. Uma variação desse mesmo impulso é a publicação de obras que procuram explicitar os caminhos percorridos pelo ofício histórico. Nessa perspectiva, um breve levantamento, a partir do ano de 2010, permite identificar as iniciativas de Estevão de Rezende Martins (2010), Jurandir Malerba (2010), bem como as de Fernando Novais e Rogério Forastieri (2011), cujos livros possibilitam ao leitor brasileiro um contato mais estreito com textos e intervenções relacionados à trajetória moderna do ofício histórico. ${ }^{1}$ As iniciativas amealharam boa repercussão, na medida em que tanto o projeto de Malerba (2013b) quanto o empreendimento de Novais e Forastieri (2013) ganharam um segundo e complementar volume. ${ }^{2}$

No primeiro momento do projeto de Malerba, objeto desta resenha resumo, o mote principal que serviu de critério para a reunião dos textos é, conforme sugere o subtítulo, "O caminho da ciência no longo século XIX". O organizador reconhece, todavia, que a "ciência" não pressupõe uma convergência de concepções, mas, ao contrário, expõe a multiplicidade de perspectivas referentes à escrita da história (MALERBA 2010, p. 8). Aliás, o caráter múltiplo da obra precisa ser ressaltado: o longo século XIX perfaz, de fato, um largo espaço de tempo - os textos cobrem um período que se inicia em 1765 e se encerra em 1930 -, e a obra contempla artigos publicados originalmente em variados idiomas - sobretudo francês, mas também alemão e inglês.

É necessário, portanto, apresentar esse volume que, no dizer de Malerba, foi "feito por historiadores" (MALERBA 2010, p. 7). A cada historiador brasileiro coube, assim, a elaboração de um pequeno texto introdutório - ora com caráter de biografia intelectual, ora centrado principalmente na vida do autor selecionado que busca situar a intervenção desses "grandes mestres que deixaram um legado monumental para o pensamento moderno" (MALERBA 2010, p. 7). Seguirei, pois, semelhante estrutura: nesta breve descrição procuro indicar o mestre, o excerto selecionado de sua obra e o historiador encarregado de sua contextualização.

A coleção de textos se inicia com a tradução do verbete História escrito por Voltaire e incluído na Encyclopédie. A opção é justificada pelo organizador: "Voltaire anuncia, em alguma medida, as preocupações básicas da história científica pela qual se lutaria 50 anos depois: a explicação dos acontecimentos históricos, o rigor na pesquisa documental, a busca da verdade" (MALERBA 2010, p. 12). Daniela Kern elabora as introduções concernentes a Voltaire e Pierre Daunou; o segundo mestre contemplado na genealogia da história científica. De Daunou, é reproduzida a conferência professada na abertura do curso de história do Collège de France em 1819. No texto, percebe-se que uma de suas preocupações principais refere-se à exposição dos fatos:

\footnotetext{
${ }^{1}$ Para um detalhamento das obras, Cf. as resenhas, publicadas em História da historiografia, sobre as coletâneas de Martins e de Novais e Forastieri: BENTIVOGLIO 2012; MALERBA 2013a.

2 Enquanto as obras organizadas por Novais e Forastieri versam sobre a Nova história e seus legados, o segundo volume de Lições de história aborda principalmente questões relativas ao historicismo e sua crise.
} 
O historiador capaz de nos instruir é aquele que possui a arte de conservar dos fatos que expõe o interesse que possuíam quando eram espetáculos, e que lhes devolve mesmo de modo tão pleno essa característica que assistimos, com efeito, a todas as cenas que nos retraça (DAUNOU 2010, p. 84).

Coube a Lilia Moritz Schwarcz recuperar dois breves excertos de Jules Michelet, a saber: o "Prefácio de 1868" e "Do método e do espírito deste livro". A seleção se legitima, sugere a comentarista, porque os trechos abordam não somente questões metodológicas, mas também indicam os argumentos principais da obra micheletiana: o povo, a crença popular e a tradição oral (SCHWARCZ 2010, p. 95-96). Nas palavras do próprio historiador: "Essa é a primeira missão da história: redescobrir por meio das pesquisas conscienciosas os grandes fatos da tradição nacional" (MICHELET 2010, p. 107).

Teresa Malatian apresenta François-René Auguste de Chateaubriand, que participa da coletânea com o seu "Prefácio" ao Études historiques, de 1843. Após identificar e apontar as virtudes e malefícios de diferentes sistemas e escolas de escrita da história, Chateaubriand conclui que apenas um critério deve regular a historiografia: "cada historiador a escreve segundo seu próprio gênio; um a conta bem, outro a pinta melhor; este aqui é sentencioso, aquele outro, indiferente ou patético, incrédulo ou religioso: toda matéria é boa, desde que verdadeira" (CHATEAUBRIAND 2010, p. 129).

As diversas posições francesas são, então, substituídas pelas reflexões prussianas sobre o desenvolvimento da ciência histórica. Inicialmente, Leopold von Ranke ganha voz a partir, especificamente, de seu texto "Sobre o caráter da ciência histórica". Julio Bentivoglio procura demonstrar a inviabilidade da caracterização de Ranke como um historiador positivista (BENTIVOGLIO 2010, p. 137). Como se percebe a partir do próprio texto rankeano, a história é concebida, simultaneamente, como ciência e arte e se aproxima, por um lado, da filosofia e, por outro, da poesia (RANKE 2010, p. 141).

Contemporâneo de Ranke, Georg Gervinus, por sua vez, foi o responsável pela criação da expressão teoria da história (Historik) que, segundo sua concepção, deveria ser abordada como um campo autônomo dos estudos históricos (BENTIVOGLIO 2010, p. 156). Um dos interesses principais de Gervinus diz respeito ao estabelecimento da identidade alemã. Bentivoglio argumenta:

Gervinus acreditava que a educação e a cultura deveriam ser responsáveis pela formação de uma identidade nacional comum alemã, e não as armas. Seus estudos sobre a história ou a literatura podem ser vistos como narrativas sobre a construção dessa identidade nacional alemã (BENTIVOGLIO 2010, p. 163).

O texto contemplado é o "Prefácio" à obra Einleitung in die Geschichte des Neunzehnten Jahrhunderts, datada de 1853.

Marx participa da coletânea, mas apenas de forma indireta. Nenhum escrito seu foi selecionado para ilustrar os caminhos da historiografia durante o século XIX, porque sua produção já circula em língua portuguesa (MALERBA 2010, p. 
11). Leandro Konder, em texto analítico, procura apontar que o autor de 018 de brumário de Luís Bonaparte apregoava uma "genuína história social", isto é, defendia que a história poderia servir como base para a modificação da sociedade. Nas palavras do comentarista: "Na perspectiva de Marx, de fato, a história tem sido o processo de modificações nas condições de trabalho dos seres humanos. $\mathrm{E}$ para os seres humanos fazerem as mudanças que consideram necessárias, eles precisam pensar e agir historicamente" (KONDER 2010, p. 177).

Após as concepções de história de língua alemã, os britânicos adquirem espaço na coletânea de Malerba. O próprio organizador introduz o texto de Thomas Carlyle ressaltando o valor concedido pelo autor ao conteúdo emocional e intuitivo na escrita da história (MALERBA 2010, p. 194). O artigo selecionado - intitulado Sobre a história, de 1830 - destaca o conhecimento histórico como intrínseco ao pensamento humano, ao mesmo tempo em que aponta as diferenças entre a ocorrência dos eventos e a percepção do homem acerca deles (CARLYLE 2010, p. 202).

A incursão pelas concepções de história em língua inglesa prossegue com Thomas Babington Macaulay, apresentado por Sérgio Campos Gonçalves. De acordo com o texto selecionado, História (1828), cabe ao historiador tornar sua narrativa envolvente e pitoresca (MACAULAY 2010, p. 217). Nesse sentido, inúmeras aproximações entre o ofício histórico, a pintura e o drama são elaboradas. As semelhanças não ocorrem apenas na composição dos discursos, mas nos limites das narrativas: "Nenhuma pintura, então, e nenhuma história 202 podem nos oferecer a verdade completa: mas as melhores pinturas e as melhores histórias são aquelas que exibem tais partes da verdade como produto realizado mais próximo do todo" (MACAULAY 2010, p. 224).

Lord Acton encerra o incurso de língua inglesa pela ciência da história na coletânea. Seu texto se deriva da aula "Do estudo da história", proferida em 1895, e contém um acentuado cunho moral. Como sintetiza Malerba, comentarista da intervenção de Acton, cabe ao historiador avaliar e julgar o conteúdo moral do passado, pois, enquanto os eventos se alteram, a moralidade permanece imutável (MALERBA 2010, p. 259).

Retorna-se então ao debate francês a partir de Louis Bourdeau. De acordo com Marco Antônio Lopes, o historiador francês seria um representante do que se denominou história positiva (LOPES 2010, p. 289). O texto selecionado, de 1888, intitula-se "Lei geral da história do progresso" e, como o título antecipa, procura sustentar o progresso como um fato característico da evolução humana.

A noção de uma história científica também é cara a Fustel de Coulanges. Segundo o autor, para concretizar essa cientificidade, o conhecimento histórico deveria apoiar-se no documento. Temístocles Cezar recorda que, além disso, Fustel de Coulanges advogava o apagamento do historiador e de seu tempo da narrativa historiográfica: somente assim a história poderia se tornar uma ciência pura (CEZAR 2010, p. 316). A coletânea traz dois breves textos do historiador francês: a sua aula inaugural do curso de História da Faculdade de Estrasburgo, de 1862, e o artigo "Regras de uma história imparcial". Neste, o historiador francês pontifica: "O estudo da história deve ter ao menos esta vantagem de 
nos acostumar a distinguir nos fatos e na marcha das sociedades aquilo que é aparente daquilo que é real, aquilo que é ilusão dos contemporâneos daquilo que é verdadeiro" (FUSTEL DE COULANGES 2010, p. 322).

Gabriel Monod, embora criticado por Fustel de Coulanges, também defendia uma história científica e objetiva. A receita poderia ser encontrada na adoção de uma metodologia específica. Conforme resume Teresa Malatian: "Um método baseado na concepção da história como ciência positiva, conhecimento fundamentado em documentos a serem criticamente analisados, para que do crivo da crítica surgisse a verdade sob a forma de fato histórico" (MALATIAN 2010, p. 326). O texto selecionado denomina-se "Do progresso dos estudos históricos na França desde o século XVI" e inaugura a Revue historique. Monod, no encerramento de seu manifesto, aponta, então, o escopo do trabalho histórico: "É assim que a história, sem se propor outro objetivo e outra finalidade que o proveito que se tira da verdade, trabalha de maneira secreta e segura para a grandeza da pátria e, ao mesmo tempo, para o progresso do gênero humano" (MONOD 2010, p. 352).

Tereza Kirschner apresenta Ernest Lavisse, autor que aderiu às prerrogativas sugeridas por Monod. Embora não tenha escrito textos de caráter metodológico, Lavisse defendia a profissionalização da história de modo a marcar a distinção entre os historiadores e os demais ofícios (KIRSCHNER 2010, p. 355-356). Em seu texto "Do determinismo histórico e geográfico", de 1879, Lavisse procura destacar tanto as diferenças evolutivas entre variados espaços quanto a importância do meio para esses desenvolvimentos diversos.

Inspirados no manifesto de Monod, Charles-Victor Langlois e Charles Seignobos almejaram institucionalizar a disciplina histórica na França. Em 1898, ambos publicaram a obra Introdução aos estudos históricos, concebida como o manual da escola metódica. Esse "movimento", contudo, passou a ser alvo de críticas, após a virada do século, seja de historiadores, como Paul Lacombe, seja de sociólogos, como François Simiand. Helenice Rodrigues Silva traz, então, dois textos, sendo um deles "O método histórico aplicado às ciências sociais", escrito em parceria com Langlois, no qual se explicita o caráter indireto do conhecimento histórico. Para os autores: "é preciso, inicialmente, aplicar o método histórico às ciências sociais para interpretar os documentos de que necessitamos, para todos os casos em que o conhecimento só pode ser indireto"; e, em seguida, arrematam "- e, na prática, quase todos os fatos das ciências sociais são coletados pelo método indireto" (SEIGNOBOS; LANGLOIS 2010, p. 391).

Paul Lacombe, crítico da dita escola metódica, procura, de acordo com Raimundo Barroso Cordeiro Júnior, distinguir e afastar a história da sociologia, da arte e da literatura, e aproximá-la, antes, da psicologia (CORDEIRO JÚNIOR 2010, p. 396-397). No texto "O domínio da história ciência e seus limites", de 1930, Lacombe tenciona desvelar as relações entre o particular e o geral na história. Nas suas palavras: "Os atores históricos agem em parte como os representantes de certo meio, é certo; digo mais, eles agem também como homens universais; mas afirmar que nada de particular, de próprio neles, não passa do papel que desempenham é ir contra a evidência" (LACOMBE 2010, p. 410). 
Henri Berr também se destacou pela fundação de um periódico, a Revue de synthèse historique. José Carlos Reis informa que Berr foi também um dos pais inspiradores dos Annales. Contudo, Marc Bloch e Lucien Febvre o criticaram pela sua ênfase demasiada nas questões teóricas (REIS 2010, p. 415). Um de seus temas diletos, a noção de síntese, aparece no extrato selecionado para a coletânea: Erudição, filosofia da história e síntese (1911). O comentarista busca resumir a relação entre estes elementos: "O lugar da síntese histórica é entre dois mundos: o da análise erudita e o da especulação a priori. A filosofia da história não pode ser eliminada sem ser substituída e será substituída pela síntese histórica científica" (REIS 2010, p. 419).

O trajeto pelo percurso da cientifização da história se encerra, enfim, com Ernst Troeltsch. De formação teológica, Troeltsch elabora um caminho relativamente comum nesse período ao se aproximar dos estudos históricos, assegura Sérgio da Mata (MATA 2010, p. 436). No texto A crise atual da história, de 1922, o historiador alemão sugere que os obstáculos do ofício não se encontram nos métodos e recursos empregados, mas nas questões que o regem, nos seus fundamentos. Cito-o: "a crise reside nos elementos e nas implicações filosóficas da pesquisa histórica, naquilo que se pode chamar sua interação com e seu significado para a visão de mundo, embora a relação seja plenamente recíproca [...]" (TROELTSCH 2010, p. 454).

A seleção dos dezoito mestres - com ênfase em textos de língua francesa pressupõe a constituição de uma determinada genealogia em relação à temática 204 da história como ciência. Seria possível conceber a coletânea, assim, como reveladora e, ao mesmo tempo, como participante de uma específica memória disciplinar. Conforme sugere Temístocles Cezar, ao comentar a posição de destaque geralmente atribuída a Wilhelm von Humboldt nessa trajetória, "Não há nesse início decididamente arbitrário, de genealogia rumo à ciência, vias expressas e destinos inexoráveis." (CEZAR 2010, p. 315). Assim, é certo que a constituição científica da história contempla muitos desses textos e autores. Contudo, é necessário destacar que esse caminho não é linear - como reconheceu o próprio organizador do volume - e também não parece convergente. A recuperação das diferentes concepções acerca do ofício, expressas nos excertos acima, demonstra, pois, que a ciência histórica, durante o período abarcado, não foi capaz de constituir-se de modo homogêneo. Pelo contrário, é possível sugerir, a partir da variedade de métodos e abordagens, a variabilidade da ciência da história, isto é, a existência, antes, de ciências da história.

Por fim, é válido evocar as contribuições da obra que se propõem a refletir sobre o ofício para, justamente, indagar sobre a própria seleção dos autores e também sobre as ausências - inevitáveis por certo - nesse caminho. Afinal, a amplitude de autores e suas contribuições por vezes escapa ao critério definidor da coletânea na medida em que alguns textos não tratam diretamente dos pressupostos e das implicações da história como ciência. Coube então a François Dosse a difícil tarefa de sintetizar essa longa e, por vezes, intrincada trajetória da história ao longo do século XIX. Sua abordagem, todavia, exclui muitas das intervenções contidas na própria coletânea e procura valorizar principalmente 
o desenvolvimento francês da disciplina. É certo que a síntese não se faz sem exclusão. No entanto, o texto de Dosse, ao desconsiderar muitos dos autores do volume, acaba por se distanciar da própria obra que procura introduzir.

A despeito disso, a obra de Malerba, com sua destacada reunião de especialistas, é uma contribuição fundamental para os estudos da história da historiografia. Ao inserir Lições de história na mesma tradição de livros como os de Patrick Gardiner (Theories of history) e Fritz Stern (The varieties of history) (MALERBA 2010, p. 10), o organizador, enfim, colabora para a divulgação de diferentes concepções de história e para a ampliação da bibliografia disponível sobre um período fundamental da afirmação do ofício histórico como disciplina acadêmica.

\section{Referências bibliográficas}

BENTIVOGLIO, Julio. Entre a história e o cânone: a ciência histórica oitocentista e seus textos fundadores. História da historiografia, n. 8, p. 175-186, 2012.

. Leopold von Ranke. In: MALERBA, Jurandir (org.). Lições de história: o caminho da ciência no longo século XIX. Rio de Janeiro: Editora FGV, 2010, p. 133-141.

. Gervinus. In: MALERBA, Jurandir (org.). Lições de história: o caminho da ciência no longo século XIX. Rio de Janeiro: Editora FGV, 2010, p. 155164.

CARLYLE, Thomas. Sobre a história. In: MALERBA, Jurandir (org.). Lições de

história: o caminho da ciência no longo século XIX. Rio de Janeiro: Editora FGV, 2010, p. 196-209.

CEZAR, Temístocles. Fustel de Coulanges. In: MALERBA, Jurandir (org.). Lições de história: o caminho da ciência no longo século XIX. Rio de Janeiro: Editora FGV, 2010, p. 307-317.

CHATEAUBRIAND. Prefácio (Études Historiques). In: MALERBA, Jurandir (org.). Lições de história: o caminho da ciência no longo século XIX. Rio de Janeiro: Editora FGV, 2010, p. 119-131.

CORDEIRO JÚNIOR, Raimundo Barroso. Paul Lacombe. In: MALERBA, Jurandir (org.). Lições de história: o caminho da ciência no longo século XIX. Rio de Janeiro: Editora FGV, 2010, p. 393-399.

DAUNOU, Pierre. Discurso de abertura [...]. In: MALERBA, Jurandir (org.). Lições de história: o caminho da ciência no longo século XIX. Rio de Janeiro: Editora FGV, 2010, p. 72-89.

FUSTEL DE COULANGES. Regras de uma história imparcial. In: MALERBA, Jurandir (org.). Lições de história: o caminho da ciência no longo século XIX. Rio de Janeiro: Editora FGV, 2010, p. 318-322.

KIRSCHNER, Tereza Cristina. Ernest Lavisse. In: MALERBA, Jurandir (org.). Lições de história: o caminho da ciência no longo século XIX. Rio de 
Janeiro: Editora FGV, 2010, p. 353-361.

KONDER, Leandro. A história em Marx. In: MALERBA, Jurandir (org.). Lições de história: o caminho da ciência no longo século XIX. Rio de Janeiro: Editora FGV, 2010, p. 173-189.

LACOMBE, Paul. O domínio da história ciência e seus limites. In: MALERBA, Jurandir (org.). Lições de história: o caminho da ciência no longo século XIX. Rio de Janeiro: Editora FGV, 2010, p. 399-412.

LOPES, Marcos Antônio. Louis Bourdeau. In: MALERBA, Jurandir (org.). Lições de história: o caminho da ciência no longo século XIX. Rio de Janeiro: Editora FGV, 2010, p. 287-297.

MACAULAY, Thomas Babington. Historia. In: MALERBA, Jurandir (org.). Lições de história: o caminho da ciência no longo século XIX. Rio de Janeiro: Editora FGV, 2010, p. 216-247.

MALATIAN, Teresa. Gabriel Monod. In: MALERBA, Jurandir (org.). Lições de história: o caminho da ciência no longo século XIX. Rio de Janeiro: Editora FGV, 2010, p. 323-332.

MALERBA, Jurandir (org.). Prefácio. In: Lições de história: o caminho da ciência no longo século XIX. Rio de Janeiro: Editora FGV, 2010, p. 7-14. . Thomas Carlyle. In: . Lições de história: o caminho da ciência no longo século XIX. Rio de Janeiro: Editora FGV, 2010, p. 191-196. . Lord Acton. In: . Lições de história: o caminho da ciência no longo século XIX. Rio de Janeiro: Editora FGV, 2010, p. 249-260.

A velha Nova História. História da historiografia, n. 11, p. 279-286, 2013a.

. (org.). Lições de história: da história científica à crítica da razão metódica no limiar do século XIX. Rio de Janeiro: Editora FGV; Porto Alegre: Edipucrs, 2013b.

MARTINS, Estevão de Rezende (org.). A história pensada: teoria e método na historiografia europeia do século XIX. São Paulo: Contexto, 2010.

MATA, Sérgio da. Ernst Troeltsch. In: MALERBA, Jurandir (org.). Lições de história: o caminho da ciência no longo século XIX. Rio de Janeiro: Editora FGV, 2010, p. 433-448.

MICHELET, Jules. Do método e do espírito deste livro. In: MALERBA, Jurandir (org.). Lições de história: o caminho da ciência no longo século XIX. Rio de Janeiro: Editora FGV, 2010, p. 100-112.

MONOD, Gabriel. Do progresso dos estudos históricos na França desde o século XVI. In: MALERBA, Jurandir (org.). Lições de história: o caminho da ciência no longo século XIX. Rio de Janeiro: Editora FGV, 2010, p. 332352. 
NOVAIS, Fernando; FORASTIERI, Rogério (orgs.). Nova história em perspectiva. Volume 1. São Paulo: Cosac Naify, 2011. ; (orgs.). Nova história em perspectiva. Volume 2. São Paulo: Cosac Naify, 2013.

RANKE, Leopold von. Sobre o caráter da ciência histórica. In: MALERBA, Jurandir (org.). Lições de história: o caminho da ciência no longo século XIX. Rio de Janeiro: Editora FGV, 2010, p. 141-154.

REIS, José Carlos. Henri Berr. In: MALERBA, Jurandir (org.). Lições de história: o caminho da ciência no longo século XIX. Rio de Janeiro: Editora FGV, 2010, p. 413-423.

SEIGNOBOS, Charles; LANGLOIS, Charles-Victor. O método histórico aplicado às ciências sócias. In: MALERBA, Jurandir (org.). Lições de história: o caminho da ciência no longo século XIX. Rio de Janeiro: Editora FGV, 2010, p. 382-391.

SCHWARCZ, Lilia Moritz. Jules Michelet. In: MALERBA, Jurandir (org.). Lições de história: o caminho da ciência no longo século XIX. Rio de Janeiro: Editora FGV, 2010, p. 91-98.

TROELTSCH, Ernst. A crise atual da história. In: MALERBA, Jurandir (org.). Lições de história: o caminho da ciência no longo século XIX. Rio de Janeiro: Editora FGV, 2010, p. 448-457. 